\title{
DESENVOLVIMENTO DE MUDAS DE BROMÉLIA-IMPERIAL (Alcantarea imperialis) EM DIFERENTES SUBSTRATOS
}

\author{
Development of imperial bromeliad (Alcantarea imperialis) in different substrates
}

\author{
Tatiana Michlovská Rodrigues ${ }^{1}$, Patrícia Duarte de Oliveira Paiva ${ }^{1}$, Carlos Ribeiro Rodrigues ${ }^{2}$, \\ Janice Guedes de Carvalho ${ }^{2}$, Clarissa Alves Ferreira ${ }^{1}$, Renato Paiva ${ }^{3}$
}

\begin{abstract}
RESUMO
A bromélia-imperial (Alcantarea imperialis), por ter grande importância ornamental, vem sendo depredada irracionalmente. A produção de mudas em larga escala é uma opção para conter o extrativismo desmedido, proporcionando, com isso, mudas ao mercado, sem prejuízo para o ambiente. Com o presente trabalho, objetivou-se avaliar o desenvolvimento de mudas de Alcantarea imperialis "Harms" produzidas "in vitro", cultivando-as em diferentes substratos. No experimento, foram testados diferentes proporções de casca de arroz carbonizada, areia, húmus e terra. Como adubação básica, foi utilizada a recomendada por Malavolta (1980) para mudas de abacaxi em vaso. O tratamento que proporcionou melhor resposta foi o substrato constituído de $50 \%$ de terra e $50 \%$ de casca de arroz carbonizada, produzindo plantas com 10,24 cm de altura e 19,26 cm de diâmetro de roseta.
\end{abstract}

Termos para indexação: Bromélia, substrato, Alcantarea imperialis.

\section{ABSTRACT}

Due to its ecological and ornamental importance, the imperial bromeliad (Alcantarea imperialis) has been irrationally harvested. The production of plantlets in large scale presents as an option to reduce its harvest as will as to offer how products to consumers. The objective of this work was to evaluate the developing of Alcantarea imperialis in vitro using different substrates. In this experiment, different proportions of carbonized rice husk, sand, humus and soil were evaluated. The basic fertilization used was the one recommended pineapple in vase by Malavolta (1980) for the growthgs. The substrate consisted of 50\% soil and 50\% carbonized rice husk produced largher plants with $10.24 \mathrm{~cm}$ height and $19.26 \mathrm{~cm}$ roset diameter.

Index terms: Alcantarea imperialis, imperial bromeliad, substrates.

(Recebido para publicação em 5 de maio de 2003 e aprovado em 25 de novembro de 2003)

\section{INTRODUÇÃO}

As bromélias vêm fascinando e adquirindo popularidade pela sua enorme beleza, fazendo com que sejam amplamente utilizadas em projetos paisagísticos. Isso tem acarretado sérios problemas ecológicos, pois tem ocorrido o extrativismo inadequado em seus habitats naturais, podendo, assim, colocar essa espécie em risco de extinção nessas áreas. Além da importância ornamental, essas plantas contribuem no ciclo ecológico para nossas matas, por manterem verdadeiros microecossistemas em seus filotelmos (LEME e MARIGO, 1993).

As bromélias são encontradas em diferentes condições ambientais em razão de sua facilidade de adaptação e especializações. No território brasileiro, as bromélias ocorrem principalmente na Região Leste, sendo $81,8 \%$ das espécies conhecidas localizadas na re- gião da Mata Atlântica (COSTA e FONTOURA, 1989).

As bromélias pertencem à família Bromeliaceae, e diversas são as espécies que apresentam excelente aptidão ornamental, principalmente as dos gêneros Alcantarea, Tillandsia, Vriesea, Guzmania, Aechmea, Neoregelia, Nidularium e Erystanthus, aos quais pertencem as plantas mais comercializadas (KÄMPF, 1992; ANDRADE e DEMATTÊ, 1999; SOCIEDADE BRASILEIRA DE BROMÉLIAS, 2001).

Pode-se destacar o gênero Vriesea, da subfamília Tillandsioideae, que possui inflorescências coloridas e que duram várias semanas, além de possuírem folhas verdes escuras e elegantes, o que as fazem desejáveis como plantas para ornamentação em ambientes internos. A Vriesea imperialis V. L. Harms, atualmente classificada e conhecida como Alcantarea imperialis

\footnotetext{
1. Departamento de Agricultura da Universidade Federal de Lavras/UFLA - Caixa Postal 37 - 37200-000, Lavras, MG. michlovskatati@hotmail.com, pdolivei@ufla.br.

2. Departamento de Ciência do Solo da UFLA.

3. Departamento de Biologia da UFLA.
} 
Harms, possui grande importância comercial por sua estética e imponência de formas, haste floral, tamanho e cor (NAVES, 2001). É nativa da Serra dos Órgãos, município de Teresópolis, no Estado do Rio de Janeiro, que apresenta uma Floresta Tropical Úmida de Encosta. Por ter uma exoticidade acentuada, essa espécie vem sendo amplamente utilizada em jardins. Por causa dessas características, a Alcantarea imperialis corre o risco de extinção em seu habitat natural (BROMÉLIAS..., 2001).

Uma das dificuldades encontradas pelos produtores de bromélia é a determinação de um substrato adequado para o seu desenvolvimento e adubação. Esse substrato deve ser formulado com grande praticidade, reduzidos custos de produção e utilizando quantidades adequadas de adubos, tornando, dessa forma, a produção econômica e eficiente.

Com o presente trabalho objetivou-se determinar um substrato adequado para o bom desenvolvimento de mudas de Alcantarea imperialis produzidas "in vitro".

\section{MATERIAL E MÉTODOS}

O trabalho foi desenvolvido em casa-de-vegetação do Departamento de Agricultura da Universidade Federal de Lavras (UFLA). Para o experimento, utilizou-se a bromélia-imperial (Alcantarea imperialis var. rubra), espécie de grande importância por causa de sua utilização em projetos paisagísticos. $\mathrm{O}$ material vegetal utilizado no experimento foi oriundo do Laboratório de Cultura de Tecidos da Universidade Federal de Lavras e do Jardim Botânico do Estado de São Paulo, São Paulo-SP.

Mudas foram retiradas dos tubos de ensaio e lavadas com sete meses de idade e apresentando 7,5 cm de altura produzidas in vitro, conforme protocolo estabelecido por Murashige e Skoog (1962). Foram, então, selecionadas pela uniformidade de comprimento de folhas e transferidas para bandejas de isopor de 72 células contendo substrato Plantmax ${ }^{\circledR}$, e mantidas durante 20 dias para aclimatização em estufa com nebulização intermitente. Nesse período, não receberam nenhuma adubação. Posteriormente, essas mudas foram transferidas para vaso, $\mathrm{n}^{\circ} 00$, de volume $260 \mathrm{~mL}$, contendo um dos substratos que constituíram os tratamentos, contendo uma planta por vaso.

$\mathrm{O}$ delineamento experimental utilizado foi em blocos casualizados, com 11 tratamentos constituídos de diferentes proporções de casca de arroz carbonizada, areia, húmus e terra, conforme discriminado na Tabela 1 , em quatro repetições.
Foram utilizados três vasos por parcela, totalizando 44 parcelas experimentais. Como adubação básica, foi utilizada a recomendada para mudas de abacaxi em vaso, por Malavolta (1980), em $\mathrm{mg} \mathrm{dm}^{-3}$ : 300 de N; 200 de P; 150 de $\mathrm{K} ; 75$ de $\mathrm{Ca} ; 15$ de $\mathrm{Mg}$; 50 de $\mathrm{S} ; 0,5$ de B; 1,5 de $\mathrm{Cu} ; 5$ de Fe; 0,1 de Mo e 5 de Zn. Essa adubação foi aplicada no plantio, de forma que o nitrogênio e o potássio fossem divididos em quatro aplicações iguais: a primeira no plantio e as outras em cobertura, com intervalos de 30 dias, sendo aplicados via substrato. A umidade dos vasos foi mantida pela nebulização intermitente da estufa.

O experimento foi mantido por 140 dias. Em seguida, realizou-se a avaliação observando o desenvolvimento das mudas, por meio dos parâmetros: altura de plantas, diâmetro basal, diâmetro da roseta e número de folhas. As variáveis analisadas foram submetidas à análise de variância e contraste ortogonal com auxílio do programa SISVAR ${ }^{\circledR}$. O contraste diferencia os tratamentos de acordo com interesse pessoal ou disponibilidade de material para composição dos substratos. O primeiro contraste utilizado e demonstrado na Figura 1, em Resultados e Discussão, separa composições com casca de arroz carbonizada (maior porosidade) com substrato sem esse elemento (menor porosidade). Assim, têm-se duas vertentes, citadas acima, que foram subsdivididas em substratos contendo areia e substratos sem areia (contrastes 2 e 7). Em cada grupo formado foram feitos contrastes com a presença e ausência de terra e depois com maior ou menor quantidade de terra, e desses grupos formados, foram realizados outros contrastes com a presença e ausência de húmus e, por último, realizou-se o contraste entre substratos com maior e menor quantidade de casca de arroz carbonizada.

\section{RESULTADOS E DISCUSSÃO}

Observou-se que as variáveis número de folhas e altura das plantas não apresentaram resultados significativos (Tabela 2).

Foi realizada análise de contraste para as variáveis que apresentaram resultados significativos pelo teste de F (Tabela 2). Na Figura 1 observa-se um resumo dos contrastes realizados.

Na Tabela 3 observa-se que os contrastes 1, 2 e 4 apresentaram boa resposta para diâmetro de base, ao passo que para o diâmetro de roseta melho- 
res respostas foram observadas para os contrastes $1 \mathrm{e}$ 4.

No contraste 1 analisou-se a presença de casca de arroz carbonizada nos tratamentos. Como relatado anteriormente, esse contraste apresentou-se significativo para o diâmetro de base e diâmetro de roseta com incremento de 0,0761 e $1,235 \mathrm{~cm}$, respectivamente, para os tratamentos cujos substratos continham casca de arroz carbonizada na sua composição (Tabela 3). No contraste 4, comparam-se substratos com presença de casca de arroz carbonizada e ausência de areia, com diferentes quantidades de terra, em que os parâmetros diâmetro de base e diâmetro de roseta apresentam incremento de 0,1825 e $4,0025 \mathrm{~cm}$, respectivamente, em comparação com os tratamentos com menor quantidade de terra.

TABELA 1 - Especificação da composição dos substratos utilizados em cada tratamento.

\begin{tabular}{ccccc}
\hline Tratamentos & Terra $(\%)$ & Areia $(\%)$ & Húmus $(\%)$ & $\begin{array}{c}\text { Casca de arroz } \\
\text { carbonizada (\%) }\end{array}$ \\
\hline 1 & 100 & - & - & - \\
2 & 50 & 50 & - & - \\
3 & 50 & 30 & 20 & - \\
4 & 50 & 10 & 20 & 20 \\
5 & 50 & 20 & 10 & 20 \\
6 & 50 & - & 50 & - \\
7 & 70 & 10 & 20 & - \\
8 & 70 & 10 & 10 & 10 \\
9 & 70 & - & 20 & 10 \\
10 & 50 & - & - & 10 \\
\hline
\end{tabular}

TABELA 2 - Resumo da análise de variância das variáveis número de folhas, altura (cm), diâmetro de base (cm) e diâmetro de roseta $(\mathrm{cm})$ avaliadas em Alcantarea imperialis para o desenvolvimento de mudas em diferentes substratos.

\begin{tabular}{lcccc}
\hline \multicolumn{1}{c}{ Variáveis } & F calculado & Pr. > Fc. & C.V. $(\%)$ & Média Geral \\
\hline Número de Folha & $1,423^{\text {ns }}$ & 0,2118 & 6,52 & 11,40 \\
Altura & $1,329^{\text {ns }}$ & 0,2605 & 14,31 & 10,24 \\
Diâmetro de Base & $2,153^{*}$ & 0,0512 & 9,26 & 1,204 \\
Diâmetro de Roseta & $3,023^{* *}$ & 0,0092 & 8,26 & 19,26 \\
\hline
\end{tabular}

$*, * *,{ }^{\text {ns }}$ - Significativo a 5\%, $1 \%$ e não signifivativo, respectivamente, pelo teste de $\mathbf{F}$. 


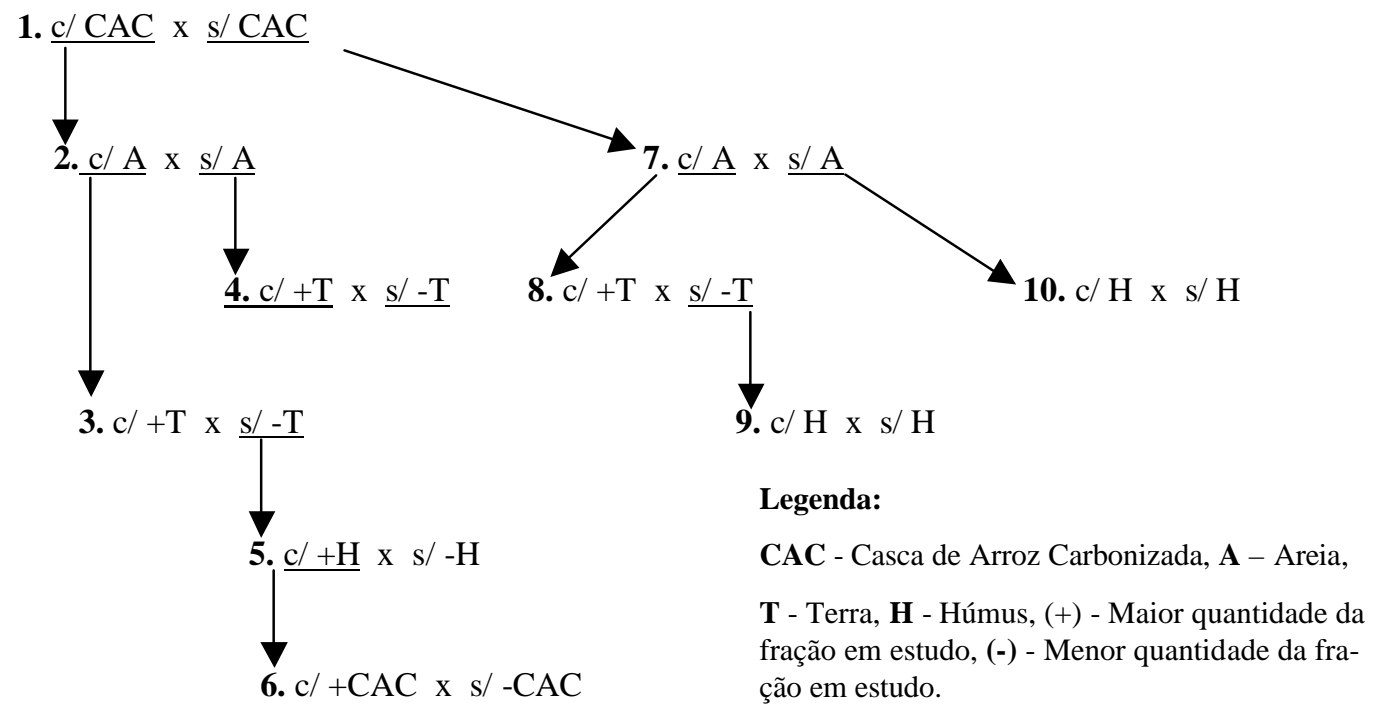

FIGURA 1 - Histograma dos contrastes realizados com as diferentes proporções dos componentes do substrato.

TABELA 3 - Significância (\%) do teste de F e estimativa dos contrastes realizados para as variáveis, diâmetro de base e diâmetro de roseta.

\begin{tabular}{ccccc}
\hline \multirow{2}{*}{ Contrastes } & \multicolumn{2}{c}{ Diâmetro de Base } & \multicolumn{2}{c}{ Diâmetro de Roseta } \\
\cline { 2 - 5 } & Significância & Estimativa & Significância & Estimativa \\
\hline 1 & 3,15 & 0,0762 & 1,56 & 1,2350 \\
2 & 1,52 & 0,1244 & 33,36 & 0,6769 \\
3 & 74,85 & $-0,0208$ & 56,16 & 0,5392 \\
4 & 2,77 & $-0,1825$ & 0,13 & $-4,0025$ \\
5 & 42,70 & $-0,0550$ & 84,67 & $-0,1900$ \\
6 & 94,99 & $-0,0050$ & 74,12 & 0,3750 \\
7 & 36,24 & $-0,0471$ & 10,88 & $-1,2000$ \\
8 & 16,90 & $-0,0962$ & 6,63 & $-1,8562$ \\
9 & 36,52 & $-0,0725$ & 53,41 & $-0,7075$ \\
10 & 92,49 & 0,0075 & 10,59 & $-1,8750$ \\
\hline
\end{tabular}

Legenda explicativa: com (componente do substrato) (+), sem (componente do substrato) (-), com + (componente do substrato) (+), com - (componente do substrato) (-).

Ciênc. agrotec., Lavras, v. 28, n. 4, p. 757-763, jul./ago., 2004 
Comparando os tratamentos envolvidos no contraste 4, ou seja, tratamentos 9 e 10 (Tabela 1), verificase que as diferenças na composição desses substratos constituem a menor quantidade de terra, maior de casca de arroz carbonizada e ausência de húmus para o tratamento 10 , o que permitiu a constituição de um substrato mais poroso, proporcionando, assim, melhor desenvolvimento das mudas, formando rosetas com maior diâmetro. Bunt (1976), Wall (1988), Tsybulya (1989), Willians e Hodgson (1990), Ballester-Olmos (1992), Kämpf (1992), Dimmitt (1992) e Foster (1953) citado por Leme e Marigo (1993) também relataram melhor desenvolvimento de bromélias em substratos que propiciaram melhor aeração das raízes. Na Figura 2 pode ser visualizado esse melhor desenvolvimento da parte aérea apresentado pelas plantas do tratamento 10 .
A casca de arroz carbonizada também apresenta baixa atividade química, em comparação ao húmus, como, por exemplo, $\mathrm{pH}$ próximo à neutralidade, rico em minerais, principalmente $\mathrm{Ca}, \mathrm{K}, \mathrm{Si}$ e CTC baixa, possibilitando, assim, maior quantidade de nutrientes em solução, isto é, maior disponibilidade desses para as plantas (MINAMI, 1995). O húmus possui alta atividade química fixando os elementos, principalmente fósforo, diminuindo a disponibilidade em solução. Esse resultado pode ser observado pela análise química dos substratos 9 e 10, apresentado na Tabela 4. O substrato que possui maiores níveis de húmus (tratamento 6) apresentou maior CTC efetiva e potencial, e menor capacidade de adsorção de $\mathrm{P}$, ou seja, alto $\mathrm{P}$ remanescente.

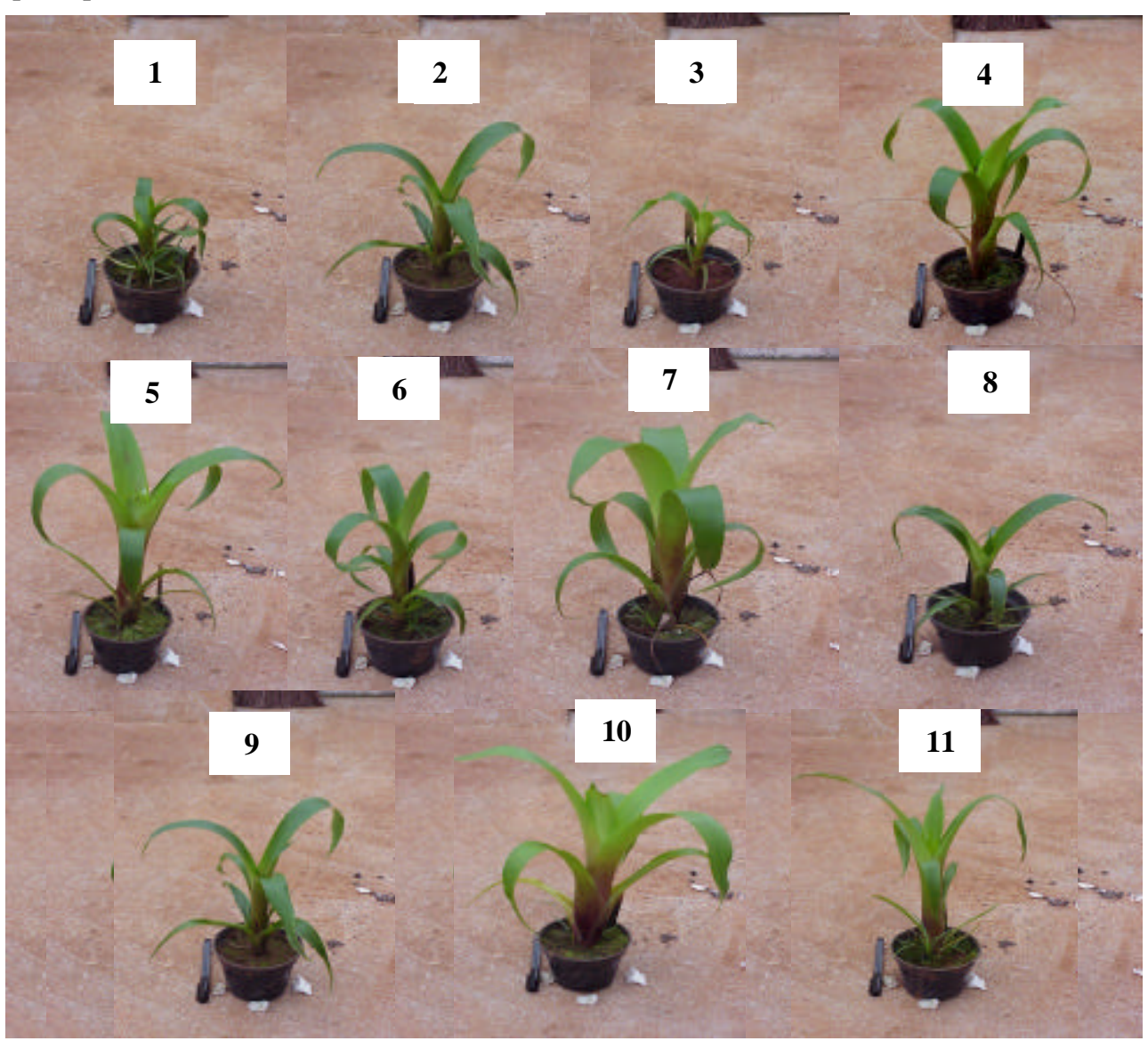

FIGURA 2 - Aspecto visual das mudas de Alcantarea imperialis cultivadas em diferentes composições do substrato. Trat $1(100 \% \mathrm{~T})$, Trat $2(50 \% \mathrm{~T}+50 \% \mathrm{~A})$, Trat $3(50 \% \mathrm{~T}+30 \% \mathrm{~A}+20 \% \mathrm{H})$, Trat $4(50 \% \mathrm{~T}+10 \% \mathrm{~A}+20 \%$ $\mathrm{H}+20 \% \mathrm{CAC})$, Trat $5(50 \% \mathrm{~T}+20 \% \mathrm{~A}+10 \% \mathrm{H}+20 \% \mathrm{CAC})$, Trat $6(50 \% \mathrm{~T}+50 \% \mathrm{H})$, Trat $7(70 \% \mathrm{~T}+10 \%$ $\mathrm{A}+20 \% \mathrm{H})$, Trat $8(70 \% \mathrm{~T}+10 \% \mathrm{~A}+10 \% \mathrm{H}+10 \% \mathrm{CAC})$, Trat $9(70 \% \mathrm{~T}+20 \% \mathrm{H}+10 \% \mathrm{CAC})$, Trat $10(50 \%$ $\mathrm{T}+50 \% \mathrm{CAC})$, Trat $11(50 \% \mathrm{~T}+10 \% \mathrm{~A}+20 \% \mathrm{H}+10 \% \mathrm{CAC})$, em que $\mathrm{T}$ (terra), A (areia), H (húmus) e CAC (casca de arroz carbonizaada). UFLA, Lavras MG, 2002.

Ciênc. agrotec., Lavras, v. 28, n. 4, p. 757-763, jul./ago., 2004 
TABELA 4 - Análise química dos substratos testados em bromélia-imperial. UFLA, Lavras MG, 2002.

\begin{tabular}{|c|c|c|c|c|c|c|c|c|c|c|c|c|c|c|c|}
\hline Trat. & PH $\mathbf{H}_{2} \mathrm{O}$ & $\mathbf{P}$ & $\mathbf{K}$ & Ca:Mg & $\mathbf{C a}$ & Mg & Al & $\mathbf{H}+\mathbf{a l}$ & $\mathbf{S B}^{(2)}$ & $\mathbf{t}$ & $\mathbf{T}$ & $\mathbf{V}$ & $\mathbf{m}$ & M.O. & P-rem \\
\hline & $(1: 2,5)$ & \multicolumn{2}{|c|}{$\mathrm{mg} \mathrm{dm}^{-3}$} & \multicolumn{8}{|c|}{$\mathrm{cmol}_{\mathrm{c}} \mathrm{dm}^{-3}$} & \multicolumn{2}{|c|}{$\%$} & $\operatorname{dag} k^{-1}$ & $\mathrm{mg} \mathrm{L}^{-1}$ \\
\hline 1 & 6,1 & 6,2 & 69,0 & 4,8 & 2,9 & 0,6 & 0,1 & 2,3 & 3,7 & 3,8 & 6,0 & 61,5 & 3,0 & 0,8 & 15,6 \\
\hline 2 & 6,3 & 6,1 & 44,0 & 22 & 2,2 & 0,1 & 0,1 & 1,7 & 2,4 & 2,5 & 4,1 & 58,6 & 4,0 & 0,1 & 21,7 \\
\hline 3 & 6,0 & 109,0 & 460,0 & 2 & 3,8 & 1,9 & 0,1 & 1,5 & 6,9 & 7,0 & 8,4 & 82,1 & 1,0 & 1,6 & 39,8 \\
\hline 4 & 6,1 & 148,0 & 607,0 & 1,6 & 4,5 & 2,8 & 0,0 & 1,7 & 8,9 & 8,9 & 10,5 & 83,9 & 0,0 & 2,5 & 37,7 \\
\hline 5 & 6,3 & 83,2 & 485,0 & 1,7 & 3,4 & 2,0 & 0,1 & 1,7 & 6,6 & 6,7 & 8,3 & 79,6 & 1,0 & 1,4 & 32,9 \\
\hline 6 & 6,1 & 478,8 & 607,0 & 1,5 & 8,1 & 5,6 & 0,1 & 1,9 & 15,3 & 15,4 & 17,2 & 88,9 & 1,0 & 6,0 & 42,2 \\
\hline 7 & 5,7 & 142,2 & 566,0 & 2,8 & 5,5 & 2,0 & 0,1 & 1,9 & 8,9 & 9,0 & 10,9 & 82,5 & 1,0 & 3,0 & 28,7 \\
\hline 8 & 6,0 & 68,5 & 450,0 & 1,9 & 4,0 & 2,1 & 0,1 & 1,9 & 7,3 & 7,4 & 9,2 & 79,2 & 1,0 & 1,8 & 27,9 \\
\hline 9 & 6,0 & 142,2 & 607,0 & 1,96 & 5,5 & 2,8 & 0,0 & 2,1 & 9,9 & 9,9 & 12,0 & 82,4 & 0,0 & 3,1 & 27,2 \\
\hline 10 & 7,1 & 73,3 & 607,0 & 1,9 & 3,0 & 1,6 & 0,0 & 1,5 & 6,2 & 6,2 & 7,7 & 80,4 & 0,0 & 1,0 & 32,9 \\
\hline 11 & 6,2 & 239,4 & 607,0 & 2,4 & 6,0 & 2,5 & 0,1 & 1,7 & 10,1 & 10,2 & 11,8 & 85,5 & 1,0 & 3,3 & 41,0 \\
\hline
\end{tabular}

Independente do material orgânico adicionado, observa-se pela análise química dos substratos que houve uma melhoria das características químicas avaliadas. Como o desenvolvimento das mudas ocorreu em vaso, não é de interesse que se obtenha um substrato com alto poder-tampão e sim um substrato que disponibilize maior quantidade de nutrientes em solução. Martinez (2002) também recomenda o uso de substratos com CTC baixa, possibilitando maior controle da concentração de nutrientes na solução nutritiva. Observa-se também que a CTC potencial de todos os substratos utilizados apresentou-se abaixo do recomendado por Martinez (2002), sendo superior a $20 \mathrm{cmol}_{\mathrm{c}} \mathrm{dm}^{-3}$.

O melhor desenvolvimento das mudas da Alcantarea imperialis foi observado em substrato com pH igual a 7,1 e com alto teor de nutrientes. Esse resultado discorda, no entanto, dos observados por BallesterOlmos (1992), que obtiveram maior crescimento de mudas de bromélias em substrato com $\mathrm{pH}$ entre 5,8 a 6,3 e com baixo teor de nutrientes.

\section{CONCLUSÕES}

As mudas de Alcantarea imperialis oriundas de propagação in vitro obtiveram bons resultados de crescimento após a aclimatização em substrato constituído de $50 \%$ de terra de subsolo e $50 \%$ de casca de arroz carbonizada.

\section{REFERÊNCIAS BIBLIOGRÁFICAS}

ANDRADE, F. S. A.; DEMATTÊ, M. E. S. P. Estudo sobre produção e comercialização de bromélia nas regiões Sul e Sudeste do Brasil. Revista Brasileira de Horticultura Ornamental, Campinas, v. 5, p. 97-110, 1999.

BALLESTER-OLMOS, J. L. Substratos para el cultivo de plantas ornamentals. Hojas Divulgadoras, Madrid, n. 11, p. 1-44, nov. 1992.

BROMÉLIAS da Mata Atlântica. Disponível em: $<$ http//www.unicamp.br/nipe/rbna/bro_dis.htm>. Acesso em: 29 ago. 2001.

BUNT, A. C. Modern potting composts. London: George Allen \& Unwin, 1976. 277 p.

COSTA, A.; FONTOURA, T. Bromélias do Rio de Janeiro. Ciência Hoje, Rio de Janeiro, n. 9, p. 8-9, 1989.

DIMMITT, M. A. Bromeliads: a cultural manual. Oregon: The Bromeliads Society, 1992. 42 p.

KÄMPF, A. N. Substratos para floricultura: manual de floricultura. In: SIMPÓSIO BRASILEIRO DE FLORICULTURA E PLANTAS ORNAMENTAIS, 1992, Maringá, PR. Anais... Maringá: [s.n.], 1992. p. 36-43. 
LEME, E. M. C.; MARIGO, L. C. Bromélia na natureza. Rio de Janeiro: Marigo Comunicação Visual, 1993. 183 p.

MALAVOLTA, E. Elementos da nutrição mineral de plantas. Piracicaba: CERES, 1980. 251 p.

MARTINEZ, P. F. Manejo de substratos para horticultura. In: ENCONTRO NACIONAL DE SUBSTRATOS PARA PLANTAS, 3., 2002, Campinas. Anais... Campinas: Instituto Agronômico, 2002. p. 53-76. (Documentos IAC, 70).

MINAMI, K. Produção de mudas em recipientes. In: Produção de mudas de alta qualidade em horticultura. São Paulo: Fundação Salim Farah Maluf, 1995. cap. 3, p. 85-101.

MURASHIGE, T.; SKOOG, F. A revised médium for rapid growth and bioassays with tobacco tissue cultures. Physiologia Plantarum, Copenhagen, v. 15, p. 473497, 1962.
NAVES, V. C. Propagação in vitro da bromélia imperial Alcantarea imperialis (Carrière) Harms. 2001. 64 p. Dissertação (Mestrado em Fitotecnia) - Universidade Federal de Lavras, Lavras, 2001

SOCIEDADE BRASILEIRA DE BROMÉLIAS. Família Bromeliaceae. Disponível em: <http://www. bromelia.org.br/famil.htm>. Acesso em: 27 ago. 2001.

TSYBULYA, N. V. Studies on the conditions for germinating seeds of bromeliads (Bromeliaceae). Biologicheskikh, [S.1.], n. 2, p. 71-74, 1989.

WALL, B. Bromeliads. London: Cassel Educational, $1988.63 \mathrm{p}$.

WILLIANS, B.; HODGSON, I. Growing bromeliads. London: Christopher Helm, 1990. 150 p. 